\section{Kidney \\ Blood Pressure Research}

\title{
Effect of Folic Acid Supplementation on Renal Phenotype and Epigenotype in Early Weanling Intrauterine Growth Retarded Rats
}

\author{
Xiaori He ${ }^{a}$ Zongde Xie ${ }^{a}$ Qingyi Dong ${ }^{a}$ Jian Lib Wen Li ${ }^{a}$ Pingyang Chen ${ }^{a}$ \\ aDepartment of Neonatology, Second Xiangya Hospital, Central South University; ${ }^{b}$ Department of \\ Clinical Medicine, Medical College of Hunan Normal University, Changsha, China
}

\section{Key Words}

Intrauterine growth retardation $\bullet$ p53 methylation $\cdot$ Glomerular volume $\bullet$ Hypertension

\begin{abstract}
Background/Aims: The objective of this study was to examine the responses of p53 promoter methylation involved in kidney structure and function of early weaning intrauterine growth retarded (IUGR) rats to dietary folic acid supplementation. Method: Sprague-Dawley rats were fed isocaloric diets containing either $21 \%$ protein diet (normal feed) or $10 \%$ protein diet throughout pregnancy and normal feed during lactation. After weaning, Offspring were then fed onto normal feed and normal feed supplemented with $5 \mathrm{mg}$ folic acid/ $\mathrm{kg}$ feed for a month, this produced 4 dietary groups (maternal diet/ weanling diet): Con, Folic, IUGR and IUGR+Folic. Renal function, renal structure, p53 promoter methylation and protein expression of offspring rats were measured at postnatal 2 months and 3 months. Results: Glomerular volume, blood urea nitrogen, 24 hours urine protein were significantly elevated in IUGR rats compared with Con rats but were decreased by dietary folic acid supplementation. p53 protein expression in IUGR rats were significantly higher than that in Con rats, and p53 promoter methylation status in IUGR rats was reduced significantly compared with Con rats. However, the changes in p53 gene expression and DNA methylation status of IUGR rats were reversed by dietary folic acid supplementation. Conclusions: Our study showed for the first time that folic acid supplementation during early period of life could reverse the abnormality in renal p53 methylation status and protein expression, glomerular volume and renal function of IUGR rats offspring.
\end{abstract}

Copyright @ 2015 S. Karger AG, Basel

\section{Introduction}

BARKER'S FETAL ORIGINAL ADULT DISEASE hypothesis proposes that a deprived intrauterine milieu leads to permanent changes in cellular biology and systemic physiology. 


\section{Kidney \\ Blood Pressure Research}

Kidney Blood Press Res 2015;40:395-402

DOI: $10.1159 / 000368516$

Published online: July 22, 2015

(c) 2015 S. Karger AG, Basel

www.karger.com/kbr

$\mathrm{He} /$ Xie/Dong/Li/Li/Chen: Folic Acid With Renal Phenotype and Epigenotype

Early stigmata of this phenotype include intrauterine growth retardation (IUGR). Several epidemiological studies closely linked IUGR to adult onset diseases such as hypertension [1-4].Our previous rats study showed that low birth weight offspring of maternal protein restriction diet exposure decreased glomerular number and impaired renal function, and caused hypertension from postnatal 2 months old [5]. However, the basic mechanism that IUGR offspring led to later renal dysfunction was not fully uncovered. Supplementation of the maternal protein-restricted (PR) [6] diet with folic acid or glycine prevents induction of hypertension and endothelial dysfunction in the offspring [7], indicating that 1-carbon metabolism is central to the mechanism underlying induction of an altered phenotype. However, most dietary folic acid intervention was implemented during intrauterine life [8$10]$, very few studies have address the question that whether folic acid supplementation in early postnatal life could also be a nutritional strategy for combating IUGR, especially reverse the renal dysfunction by maternal PR diet.

p53 is best known as a tumor suppressor that regulates cell-cycle, differentiation, and apoptosis pathways and is required for early events of metanephric development [11-13]. Our previous rats work showed that the p53 protein expression was down-regulation in low birth weight offspring kidney (under publishment). However, the deep molecular mechanisms responsible for the reduction were unknown. This study was to investigate the role of p53 methylation in maternal malnutrition programming further, and test whether dietary folic acid supplementation during early life could alleviate the negative effects that IUGR confers upon renal phenotype and p53 methylation profile in the rat offspring.

\section{Materials and Methods}

\section{Rats and experimental design}

The experimental protocols were approved by the Experimental Animal Center of the Second Xiang Ya Hospital of Central South University. Totally 16 male and 16 female three-month-old Sprague-Dawley (SD) rats (weighting 250-300 g) were involved in this study. They were acclimatized to laboratory conditions for 7 days, and then the male and female rats were placed in individual cages with a ratio of 1:1.When a vaginal plug appeared, that day was designated as gestation day 1 . Pregnant rats were randomly divided into IUGR group (IUGR) and control group (Con). The IUGR model was modified from our previous paper [5]. In IUGR, the pregnant rats were fed $10 \%$ protein diet (protein restriction feed) only during pregnancy, and $21 \%$ protein diet (normal feed) during lactation. The pregnant rats in Con were fed normal feed during pregnancy and lactation. At weaning, offspring of two groups were randomly assigned to normal feed or normal feed supplemented with $5 \mathrm{mg}$ folic acid/kg feed for a month after weaning, which was specifically selected to represent the juvenile-pubertal period. This produced 4 dietary groups (maternal diet/weanling diet): Con, Folic, IUGR, and IUGR+Folic. The dose of folic acid used in the study was according to the observations in earlier reports [9, 14]. From postnatal 2 months, all of rats were given normal feed until postnatal 3 months.

The animals were housed in a room with a controlled temperature and a 12-h light/dark cycle. the composition of diet was described in our previous study [5]. The animals were allowed free access to water and feed. There were 8-10 offspring in every nest during lactation, excluding the nest with more than 14 offspring or less than 8 . When the offspring were weaning at postnatal 21 days, all of the rats were marked, and the serial number was divided into 8 rats per group according to random number table. Then the random group rats entered the subsequent study at every time point. The method is consistent to the previous studies $[15,16]$. Twenty-four hours urine sample, blood samples and tissue samples were collected at the age of 21 days, 2 months and 3 months. Postnatal 21 days was weaning time. Postnatal 2 months was intervention terminal time. Postnatal 3 months was specially chosen because it is time point of rats adulthood and adult disease emergence based on our previous work [5]. The kidney samples were taken within $5 \mathrm{~min}$ after sacrifice. A half of right kidney was snap frozen in liquid nitrogen before being stored at $-80^{\circ} \mathrm{C}$, and a half of right kidney was stored in $4 \%$ paraformaldehyde for histology study. The measurement method of serum creatinine (Scr), blood urea nitrogen (BUN), $24 \mathrm{~h}$ urine protein and glomerular number was detailed described in our previous paper [5]. 


\section{Kidney \\ Blood Pressure Research}

$\mathrm{He} / \mathrm{Xie} /$ Dong/Li/Li/Chen: Folic Acid With Renal Phenotype and Epigenotype

\section{Determination of Glomerular Volume}

Glomerular volume was determined according to the method described by Manalich et al [17].the kidneys were bisected and immersed in 4\% paraformaldehyde. After 10 days, halves of the kidney samples were cut into slices $4 \mathrm{~mm}$ thick. Histomorphometric analyses were done by a renal pathologist who was blinded as to the origin of the biopsy. After stained with hematoxylin and eosin, Analyses were done with the help of a computerized area measurement system supported by Windows XP that includes capture of the image from an Nikon Eclipse E400 microscope and digitalization of this image (SONY DSC-W55). 20 glomerulis of every slice were selected to glomerular area (A). The glomerular volume was calculated with the use of the following formula:

$$
\mathrm{G}=((\beta / \mathrm{K}) \times \mathrm{A})^{3 / 2}
$$

Where $\beta=1.38$ is the shape coefficient of spheres, and $\mathrm{k}=1.1$ the size distribution coefficient. $\mathrm{A}$ is the glomerular size.

\section{Western blotting}

Homogenates from renal were prepared in $400 \mu \mathrm{l}$ of RIPA lysis buffer (Applygen, China) using a Dounce homogenizer. Homogenates were incubated for $1 \mathrm{~h}$ at $4{ }^{\circ} \mathrm{C}$ and centrifuged at $10,000 \times g$ for 30 $\min$ at $4{ }^{\circ} \mathrm{C}$. Protein in the supernatants was measured using the BCA protein quantitative kit (well biology, china). For immunoblotting, proteins (30-60 $\mu \mathrm{g}$ ) were separated by $12.5 \%$ SDS-PAGE and transferred to polyvinylidenedifluoride membranes. Blots were incubated with rabbit polyclonal anti-rats p53 (1:3000) antibodies(CST, USA). The primary antibodies were detected using horse radish peroxidaseconjugated goat anti- rabbit IgG (1:1000) antibodies (BOSTER, china). Bands were visualized by enhanced chemiluminescence (Applygen, China).

\section{Bisulfite Modification and Bisulfite Genomic Sequencing}

Genomic DNA was isolated using the AURAGENE Genomic DNA Purification Kit (AURAGENE, China) according to the manufacturer's protocol. The size of DNA estimated by agarose-gel electro-phoresis was $>10 \mathrm{~kb}$ in all instances. The 8 genomic DNA of every group were mixed together. The methylation status of individual $\mathrm{CpG}$ sites within the promoter region of the $\mathrm{p} 53$ gene was determined by the sodium bisulfite-sequencing assay using the EZ DNA Methylation-Gold ${ }^{\mathrm{TM}}$ Kit (ZYMO RESEARCH, USA) according to the manufacturer's protocol. In the DNA bisulfite modification, unmethylated cytosine is converted to uracil, whereas methylated cytosine remainsunchanged. The following are PCR primers, p53-BSPF:TAATTAAAAGTAAATAGA; p53-BSP-R: ATCTTATTTCAAAATTAC (BGI, China) which amplify a 365 bp product. The PCR conditions were: denaturation at $94^{\circ} \mathrm{C}$ for $4 \mathrm{~min}, 35$ cycles at $94^{\circ} \mathrm{C}$ for $30 \mathrm{~s}, 56^{\circ} \mathrm{C}$ for $30 \mathrm{~s}$ and $72^{\circ} \mathrm{C}$ for $30 \mathrm{~s}$. The purified PCR products were cloned into pMD18-T Vector using the pMD18-T Vector (Takara, Japan) according to the manufacturer's protocol. 20 positive clones of every group were sequenced.

\section{Statistical Analyses}

Data were analyzed using SPSS version 20.0 (SPSS, Inc, Chicago, IL, USA). All results were shown in the form of mean \pm standard deviation (mean \pm SD). Student's t-test was performed to detect differences in means between the two groups and chi-square $(\chi 2)$ test for proportion differences. Statistical significance of the differences between four groups was determined by two-way ANOVA, followed by LSD-t test. A P value less than 0.05 was considered statistically significant.

\section{Results}

\section{IUGR Model Building}

16 female rats became pregnant after continuing circular mating for 14 days. All pregnant rats labored during gestation day 20-23, without miscarriage. Table 1 shows the baseline characteristics of the Con and IUGR during perinatal period. There was no difference in the average litter size between the groups. The body weight of offspring was significantly lower in IUGR (5.59 $\pm 0.55 \mathrm{~g})$ compared to Con $(6.95 \pm 0.64 \mathrm{~g})(\mathrm{p}<0.01)$, which was accompanied with higher incidence of low birth weight offspring rats. 


\section{Kidney Blood Pressure Research}

Table 1. Baseline characteristics of the study groups in perinatal period

\begin{tabular}{ccccccc}
\hline & $\begin{array}{c}\text { Pregnant } \\
\text { rat number }\end{array}$ & $\begin{array}{c}\text { Total offspring } \\
\text { number }\end{array}$ & $\begin{array}{c}\text { Mean number of } \\
\text { Offspring per litter }^{\mathrm{a}}{ }^{\mathrm{a}}\end{array}$ & $\begin{array}{c}\text { Average birth weight } \\
\text { of offspring rats (g) }^{\mathrm{a}}\end{array}$ & $\begin{array}{c}\text { Number of LBW } \\
\text { offspring rats }(\%)^{\mathrm{b}}\end{array}$ & $\begin{array}{c}\text { Perinatal } \\
\text { mortality (\%) }\end{array}$ \\
\hline Con & 8 & 86 & $10.75 \pm 1.58$ & $6.95 \pm 0.64$ & $3(3.49)$ & $4(4.65)$ \\
IUGR & 8 & 92 & $11.50 \pm 0.93$ & $5.59 \pm 0.55^{* *}$ & $70(76.09)^{* *}$ & $8(8.70)$ \\
\hline
\end{tabular}

aValues are presented as means \pm SD. bLBW (low birth weight) was defined as less than average birth weight of offspring rats in the control group minus two standard deviations. ${ }^{* *} \mathrm{p}<0.01$ compared with control group

Growth after birth

Table 2 presents the baseline data between IUGR and Con, there is no difference with body weight, kidney weight in postnatal 21 days. Table 3 presents the comparison of body weight and kidney weight in four groups at at any time point between Con and Folic. Comparing with the offspring in Con, the body weight and the kidney weight were significantly lower in IUGR at postnatal 2 months, while there was no difference at postnatal 3 months. The offspring rats in IUGR exhibited stage catch-up growth after weaning, which agreed well with the previous report [5]. The body weight and kidney weight of IUGR+Folic at postnatal 2 months is lower than the Con. While body weight of IUGR+Folic at postnatal 3 months was lower than Con, but the kidney weight reached Con (for details, see in table 2).

\section{Renal Function}

The baseline data with renal function (Scr, BUN, $24 \mathrm{~h}$ urine protein) between IUGR and Con was not different in postnatal 21 days (see in table 2).The comparison of Scr, BUN and $24 \mathrm{~h}$ urine protein at postnatal 2 months and 3 months between the 4 groups is shown in table 3. There was no difference in Scr between the four groups at the age of 2 months and 3 months, and there was no difference in BUN and $24 \mathrm{~h}$ urine protein between the four groups at the age of 2 months. However, BUN and $24 \mathrm{~h}$ urine protein of the IUGR was higher than the Con $(\mathrm{p}<0.05)$ at 3 months of age. The renal function can be rescued by folic acid supplementation, BUN and $24 \mathrm{~h}$ urine protein was lower in IUGR+Folic than IUGR $(\mathrm{p}<0.05)$ at 3 months of age.

\section{Glomerular Number and Volume}

In IUGR pups, maternal protein restriction diets significantly reduced offspring glomeruli per kidney section to $22187 \pm 998$ at postnatal 2 months and $22437 \pm 1015$ at postnatal 3 months $(\mathrm{P}<0.01)$. In contrast, control pups contained glomeruli per kidney section $28875 \pm 1061$ at postnatal 2 months and $29000 \pm 964$ at postnatal 3 months. When adding folic acid into the feed, the glomeruli number remained similar between postnatal 2 months and postnatal 3 months (22060 1266 and $22250 \pm 886$ respectively). There was no difference with glomerular number between IUGR and IUGR+Folic at any time point.

Table 2 presents the baseline glomerular volume data between IUGR and Con, there is no difference in postnatal21 days. The glomerular volume of the four groups was not different at postnatal 2 months. However, the glomerular volume of IUGR was significantly larger than Conat postnatal 3 months. When adding folic acid, the glomerular volume of IUGR+Folic became smaller comparing with IUGR $(100.13 \pm 16.07$ vs $116.80 \pm 13.46, P<0.01)$ (for details, see in table2 and 3). 


\section{Kidney \\ Blood Pressure Research}

Kidney Blood Press Res 2015;40:395-402

\begin{tabular}{l|l}
\hline DOI: $10.1159 / 000368516$ & C 2015 S. Karger AG, Basel
\end{tabular}

Published online: July 22, 2015

www.karger.com/kbr

Table 3. Comparison of the parameters of offspring between the four groups $(n=8)$

\begin{tabular}{|c|c|c|c|c|c|c|}
\hline & Con & Folic & IUGR & IUGR+Folic & $F$ & $P$ \\
\hline \multicolumn{7}{|c|}{ Body weight (g) } \\
\hline $2 \mathrm{~m}$ & $173.70 \pm 38.96$ & $162.16 \pm 29.99$ & $123.69 \pm 16.80^{b}$ & $121.74 \pm 14.28^{b}$ & 7.761 & 0.001 \\
\hline $3 \mathrm{~m}$ & $265.97 \pm 19.38$ & $254.14 \pm 16.77$ & $270.37 \pm 21.60$ & $241.16 \pm 20.27 \mathrm{ad}$ & 3.581 & 0.026 \\
\hline \multicolumn{7}{|c|}{ Kidney weight (g) } \\
\hline $2 \mathrm{~m}$ & $0.90 \pm 0.1088$ & $0.83 \pm 0.1280$ & $0.71 \pm 0.08^{b}$ & $0.83 \pm 0.12^{\mathrm{c}}$ & 3.26 & 0.025 \\
\hline $3 \mathrm{~m}$ & $0.97 \pm 0.0952$ & $0.95 \pm 0.0894$ & $1.03 \pm 0.12$ & $0.97 \pm 0.0948$ & 0.928 & 0.440 \\
\hline \multicolumn{7}{|c|}{ BUN (mmol/l) } \\
\hline $2 \mathrm{~m}$ & $7.27 \pm 0.79$ & $7.06 \pm 0.86$ & $7.17 \pm 0.82$ & $7.22 \pm 0.76$ & 0.102 & 0.958 \\
\hline $3 \mathrm{~m}$ & $7.03 \pm 0.98$ & $7.15 \pm 0.71$ & $8.51 \pm 1.04^{b}$ & $7.32 \pm 1.07 \mathrm{c}$ & 4.025 & 0.017 \\
\hline \multicolumn{7}{|c|}{ Scr (umol/l) } \\
\hline $2 \mathrm{~m}$ & $24.93 \pm 5.08$ & $23.96 \pm 4.55$ & $26.27 \pm 4.34$ & $25.60 \pm 4.91$ & 0.348 & 0.791 \\
\hline $3 \mathrm{~m}$ & $27.07 \pm 4.53$ & $25.91 \pm 4.89$ & $29.28 \pm 3.41$ & $27.42 \pm 3.83$ & 0.886 & 0.461 \\
\hline \multicolumn{7}{|c|}{24 h urine protein $(\mathrm{mg} / \mathrm{kg} \cdot$ day $)$} \\
\hline $2 \mathrm{~m}$ & $96.70 \pm 9.42$ & $97.20 \pm 7.78$ & $100.39 \pm 12.29$ & $101.95 \pm 10.27$ & 0.504 & 0.683 \\
\hline $3 \mathrm{~m}$ & $93.18 \pm 11.26$ & $92.32 \pm 9.39$ & $114.78 \pm 13.48^{b}$ & $98.81 \pm 12.66^{c}$ & 6.228 & 0.002 \\
\hline \multicolumn{7}{|c|}{ Glomerular Number } \\
\hline $2 \mathrm{~m}$ & $28875 \pm 1061$ & $28437 \pm 1237$ & $22187 \pm 998^{b}$ & $22060 \pm 1266^{b}$ & 86.81 & 0.000 \\
\hline $3 \mathrm{~m}$ & $29000 \pm 964$ & $29312 \pm 843$ & $22437 \pm 1015^{b}$ & $22250 \pm 886^{b}$ & 143.47 & 0.000 \\
\hline \multicolumn{7}{|c|}{ Glomerular Volume ( um $^{3} \times 10^{5}$ ) } \\
\hline $2 \mathrm{~m}$ & $74.14 \pm 12.86$ & $75.77 \pm 12.12$ & $79.65 \pm 14.76$ & $78.35 \pm 10.53$ & 0.309 & 0.819 \\
\hline $3 \mathrm{~m}$ & $89.75 \pm 15.68$ & $86.37 \pm 16.84$ & $116.80 \pm 13.46^{b}$ & $100.13 \pm 16.07 \mathrm{a}, \mathrm{c}$ & 7.784 & 0.001 \\
\hline \multicolumn{7}{|c|}{ p53 protein experession } \\
\hline $2 \mathrm{~m}$ & $0.31 \pm 0.07$ & $0.28 \pm 0.05$ & $0.48 \pm 0.05^{b}$ & $0.39 \pm 0.08$ ac & 16.89 & 0.000 \\
\hline $3 \mathrm{~m}$ & $0.16 \pm 0.032$ & $0.17 \pm 0.04$ & $0.37 \pm 0.02^{b}$ & $0.27 \pm 0.02^{\mathrm{bd}}$ & 96.48 & 0.000 \\
\hline \multicolumn{7}{|c|}{ p53 promoter mythelation } \\
\hline $3 \mathrm{~m}$ & $17.25 \pm 0.64$ & $17.05 \pm 0.61$ & $3.55 \pm 0.67$ b & $8.10 \pm 0.79$ bd & 1981.32 & 0.000 \\
\hline
\end{tabular}

Data are given as mean \pm SD. BUN: blood urea nitrogen. Scr: serum creatinine. 24 h urine protein: 24 hour urine protein. ${ }^{a} \mathrm{p}<0.05$ compared with control group, ${ }^{\mathrm{b}} \mathrm{p}<0.01$ compared with control group. ${ }^{\mathrm{c}} \mathrm{p}<0.05$ compared with IUGR group, ${ }^{\mathrm{d}} \mathrm{p}<0.01$ compared with IUGR group.

p53 protein expression and $p 53$ promoter methylation

The p53 protein expression was gradually decreased from postnatal d 1 to postnatal 3 months in both Con and IUGR (data are not shown). However, maternal protein restriction diets significantly made the p53 protein expression of IUGR higher than Con at postnatal 2 and 3 months. When the IUGR offspring adding with folic acid, the p53 protein expression of IUGR+Folic became less than IUGR, although it is still more than Con at postnatal 2 and 3 months (table 3 and figure 1).Totally, there are $18 \mathrm{CpG}$ islets in the p53 promoter. The maternal diet and folic acid supplementation affected renal p53 promoter methylation. p53 promoter methylation was significantly lower in IUGR than Con offspring, but p53 promoter methylation was greater in IUGR+Folic than IUGR offspring at postnatal 3 months (table 3 and figure 2).

\section{Discussion}

In the present study, our study demonstrated that dietary folic acid supplementation during early weaning period prevented the abnormality in p53 methylation status and renal function in IUGR rats kidney by maternal protein restriction diets. Our study implicated that folic acid supplementation in weaning IUGR rat could intervene maternal malnutrition programming successful: maternal low protein diet exposure-offspring renal p53 gene epigenotype abnormalities-offspring glomerular volume abnormalities-offspring renal dys- 


\section{Kidney \\ Blood Pressure Research}

function-offspring adult onset hypertension.

The glomerular number was decreased, BUN and 24 hour urine protein were increased in IUGR rats, which agreed well with our previous report [5] and indicated our IUGR rats model is stable. Glomerular is the base of renal function and the most components of nephron. There is an inverse relationship between nephron number and blood pressure, irrespective of whether nephron number is reduced congenitally or in postnatal life (as from partial renal ablation or acquired renal disease). Brelmer et al.'s study [18] proposed that congenital nephron number decrease is one of the important mechanisms of hypertension and renal injury. The decreasing glomerular number in IUGR coincided well with several animal study which showed that the nephron number of IUGR is decreased 15$60 \%$ and was an independent risk factor for hypertension in adulthood [19].

p53 function is required for early events of metanephric development [11-13]. In the present study, promoter methylation status of p53 was significantly decreased by $80 \%$. Studies have shown that the glomerular cell apoptosis [20] and podocyte apoptosis [21] is an important reason of kidney disease. Wild-type p53 transgenic mice exhibited that p53 transgenic kidneys grew to only half of their expected size and contained about half of the normal number of nephrons because of the loss of uncom-

$\mathrm{He} / \mathrm{Xie} / \mathrm{Dong} / \mathrm{Li} / \mathrm{Li} /$ Chen: Folic Acid With Renal Phenotype and Epigenotype

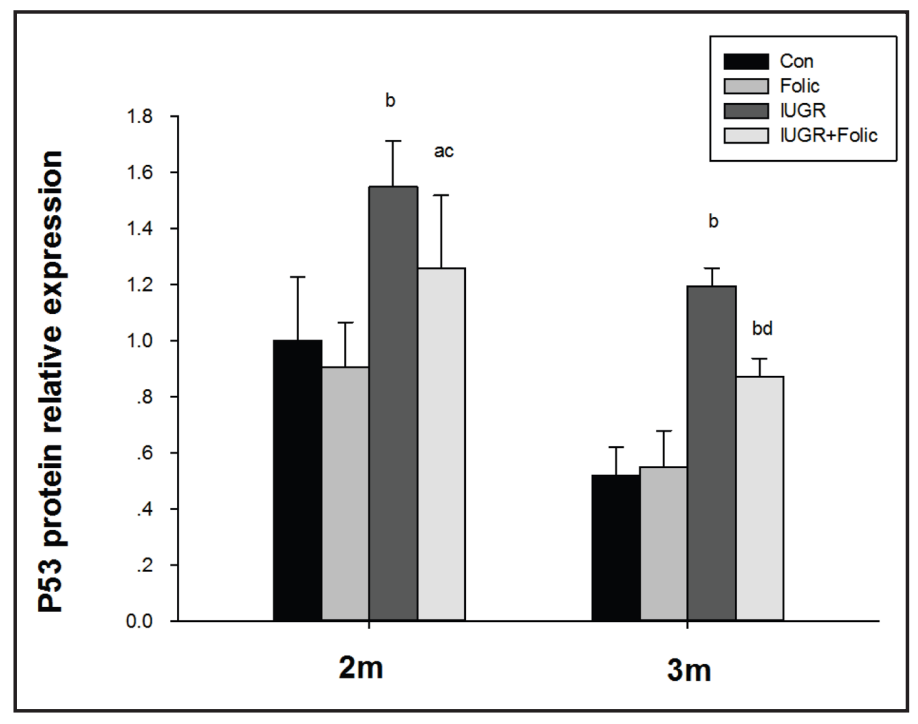

Fig 1. Comparison of the p53 protein relative experession between four groups at postnatal 2 and 3 months. Data are given as mean \pm SD. The p53 protein relative expression is the ratio of $\mathrm{p} 53$ protein band gray value to $\beta$-actin protein band gray value. Con group in $2 \mathrm{~m}$ was translated to 1 , and other group data was translated accordingly. ${ }^{\mathrm{a}} \mathrm{p}<0.05$ compared with control group, ${ }^{\mathrm{b}} \mathrm{p}<0.01$ compared with control group. ${ }^{\mathrm{c}} \mathrm{p}<0.05$ compared with IUGR group, ${ }^{\mathrm{d}} \mathrm{p}<0.01$ compared with IUGR group.

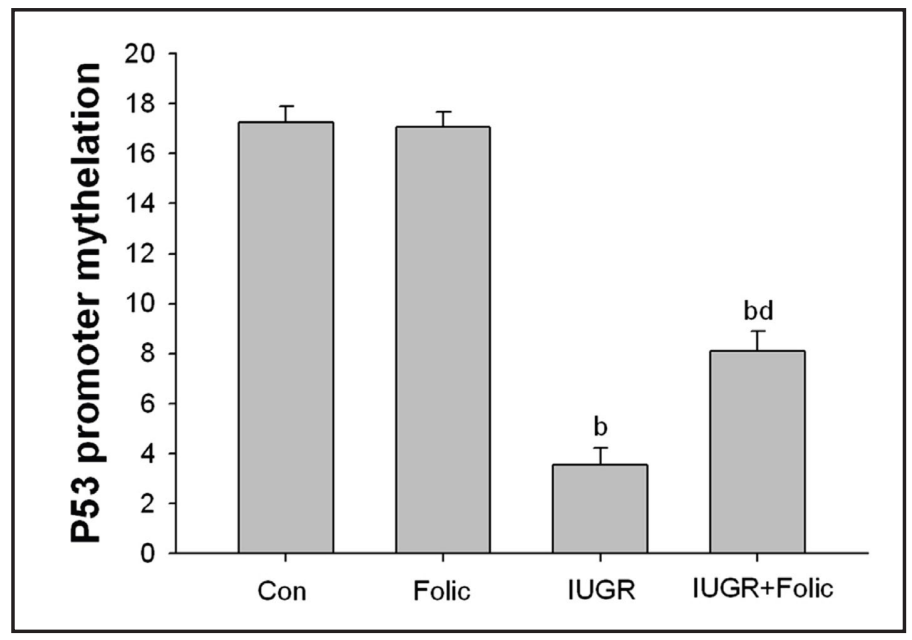

Fig 2. Comparison of the p53 promoter methylation between four groups at postnatal 3 months. Data are given as mean \pm SD. ${ }^{a} \mathrm{p}<0.05$ compared with control group, ${ }^{b} \mathrm{p}<0.01$ compared with control group. ${ }^{c} \mathrm{p}<0.05$ compared with IUGR group, ${ }^{\mathrm{d}} \mathrm{p}<0.01$ compared with IUGR group.

mitted mesenchymal cells by apoptosis [11]. Simon et al. research [22] showed protein restriction in pregnancy is associated with increased apoptosis of mesenchymal cells at the start of offspring rat metanephrogenesis. Pham et al. research [15] showed that uteroplacental insufficiency reduced p53 CpG methylation and affected mRNA levels of key apoptosis-related proteins (Bcl-2/Bax) in the kidney. Moreover, Godley et al.'s wild-type p53 transgenic mice showed that glomeruli volume was compensatory hypertrophy [23]. Decrease of glomerular 


\section{Kidney \\ Blood Pressure Research}

Kidney Blood Press Res 2015;40:395-402

DOI: $10.1159 / 000368516$

Published online: July 22, 2015

C 2015 S. Karger AG, Basel

www.karger.com/kbr

$\mathrm{He} /$ Xie/Dong/Li/Li/Chen: Folic Acid With Renal Phenotype and Epigenotype

number led to compensatory hypertrophy, high perfusion, or sclerosing necrosis of nephron, which result in hypertension [20]. Therefore, we deduced that maternal protein restriction during pregnancy altered offspring rats p53 DNA CpG methylation, increased glomerular cell apoptosis or podocyte apoptosis, reduced glomeruli number. Decrease of glomerular number led to glomerular volume compensatory hypertrophy, as the glomerular volume was increased in the IUGR rat kidney.

Abnormal one-carbon metabolism and subsequent DNA methylation abnormality were the most possible mechanisms responsible for the persistently negative effects of IUGR on the offspring. There is some information that changes in phenotype induced by nutritional constraint during early life can be reversed by effective intervention. Previous studies in rats emphasized the usage of folic acid supplementation to rescue the impaired hepatic DNA methylation and genes expressions of the offspring by maternal malnutrition during gestation period $[9,10]$. Besides gestational stage, Juvenile-pubertal period is another highly plastic stage and intervention period $[14,16]$. In this study, we supplemented IUGR rats with folic acid in Juvenile-pubertal period. We observed that p53 promoter methylation status was reversed in IUGR+Folic rats comparing with IUGR rats in postnatal 3 month. The upregulated p53 promoter methylation status was responsible for the decreased p53 protein expressions in IUGR+Folic rats. Kidney completes organ development before gestational week 36 in uterus and nephron number decreases gradually after birth. Therefore, this could be a reason for ineffectiveness of folic acid supplementation to rescue nephron numbers. However, it is worthy noting that the change in p53 promoter methylation and protein expressions were paralleled by a decrease in kidney glomerular volume, BUN and 24 hour urine protein in IUGR+Folic, suggesting that folic acid supplementation prevented glomerular compensatory hypertrophy and improved function through epigenetic pathway. The folic acid supplementation intervention effect coincided well with the studies using rats and piglets for the nutritional programming intervention experiments $[14,16]$.

\section{Conclusion}

Our results suggested that dietary folic acid supplementation during early weaning period reversed the abnormality in renal p53 methylation status and protein expression, glomerular volume and renal function of IUGR rats offspring. Our study provides insight to ameliorating the negative effects of IUGR on the offspring by nutritional strategy during early period of life.

\section{Disclosure Statement}

The authors of this manuscript state that they do not have any conflict of interests and nothing to disclose.

\section{Acknowledgment}

This study was supported by the Planned Science and Technology Project of Hunan Province(no. 2013WK3030)and in part by the Metabolic Syndrome Research Center of Central South University (no. DY-2008-02-01).

\section{References}

1 Barker DJ, Hales CN, Fall CH, Osmond C, Phipps K, Clark PM: Type 2 (non-insulin-dependent) diabetes mellitus, hypertension and hyperlipidaemia (syndrome $\mathrm{x}$ ): Relation to reduced fetal growth. Diabetologia 1993;36:62-67. 


\section{Kidney \\ Blood Pressure Research}

$\mathrm{He} / \mathrm{Xie} / \mathrm{Dong} / \mathrm{Li} / \mathrm{Li} / \mathrm{Chen}$ : Folic Acid With Renal Phenotype and Epigenotype

2 Yarbrough DE, Barrett-Connor E, Kritz-Silverstein D, Wingard DL: Birth weight, adult weight, and girth as predictors of the metabolic syndrome in postmenopausal women: The rancho bernardo study. Diabetes Care 1998;21:1652-1658.

3 Valdez R, Athens MA, Thompson GH, Bradshaw BS, Stern MP: Birthweight and adult health outcomes in a biethnic population in the USA. Diabetologia 1994;37:624-631.

4 Reichetzeder C, Chen H, Föller M, Slowinski T, Li J, Chen YP, Lang F, Hocher B: Maternal vitamin D deficiency and fetal programming--lessons learned from humans and mice. Kidney Blood Press Res 2014;39:315-329.

5 Xie Z, Dong Q, Ge J, Chen P, Li W, Hu J: Effect of low birth weight on impaired renal development and function and hypertension in rat model. Ren Fail 2012;34:754-759.

6 Langley SC, Jackson AA: Increased systolic blood pressure in adult rats induced by fetal exposure to maternal low protein diets. Clin Sci (Lond) 1994;86:217-222; discussion 121.

7 Jackson AA, Dunn RL, Marchand MC, Langley-Evans SC: Increased systolic blood pressure in rats induced by a maternal low-protein diet is reversed by dietary supplementation with glycine. Clin Sci (Lond) 2002;103:633-639.

8 Burdge GC, Lillycrop KA, Jackson AA, Gluckman PD, Hanson MA: The nature of the growth pattern and of the metabolic response to fasting in the rat are dependent upon the dietary protein and folic acid intakes of their pregnant dams and post-weaning fat consumption. Br J Nutr 2008;99:540-549.

9 Lillycrop KA, Phillips ES, Jackson AA, Hanson MA, Burdge GC: Dietary protein restriction of pregnant rats induces and folic acid supplementation prevents epigenetic modification of hepatic gene expression in the offspring. J Nutr 2005;135:1382-1386.

10 Lillycrop KA, Rodford J, Garratt ES, Slater-Jefferies JL, Godfrey KM, Gluckman PD, Hanson MA, Burdge GC: Maternal protein restriction with or without folic acid supplementation during pregnancy alters the hepatic transcriptome in adult male rats. Br J Nutr 2010;103:1711-1719.

11 Saifudeen Z, Dipp S, El-Dahr SS: A role for p53 in terminal epithelial cell differentiation. J Clin Invest 2002;109:1021-1030.

12 Saifudeen Z, Dipp S, Stefkova J, Yao X, Lookabaugh S, El-Dahr SS: P53 regulates metanephric development. J Am Soc Nephrol 2009;20:2328-2337.

13 Hilliard S, Aboudehen K, Yao X, El-Dahr SS: Tight regulation of p53 activity by mdm2 is required for ureteric bud growth and branching. Dev Biol 2011;353:354-366.

14 Burdge GC, Lillycrop KA, Phillips ES, Slater-Jefferies JL, Jackson AA, Hanson MA: Folic acid supplementation during the juvenile-pubertal period in rats modifies the phenotype and epigenotype induced by prenatal nutrition. J Nutr 2009;139:1054-1060.

15 Pham TD, MacLennan NK, Chiu CT, Laksana GS, Hsu JL, Lane RH: Uteroplacental insufficiency increases apoptosis and alters p53 gene methylation in the full-term iugr rat kidney. Am J Physiol Regul Integr Comp Physiol 2003;285:R962-R970.

16 Jing-Bo L, Ying Y, Bing Y, Xiang-Bing M, Zhi-Qing H, Guo-Quan H, Hong C, Dai-Wen C: Folic acid supplementation prevents the changes in hepatic promoter methylation status and gene expression in intrauterine growth-retarded piglets during early weaning period. J Anim Physiol Anim Nutr (Berl) DOI: 10.1111/j.1439-0396.2012.01333.x.

17 Manalich R, Reyes L, Herrera M, Melendi C, Fundora I: Relationship between weight at birth and the number and size of renal glomeruli in humans: A histomorphometric study. Kidney Int 2000;58:770-773.

18 Brenner BM, Chertow GM: Congenital oligonephropathy and the etiology of adult hypertension and progressive renal injury. Am J Kidney Dis 1994;23:171-175.

19 Brenner BM, Garcia DL, Anderson S: Glomeruli and blood pressure. Less of one, more the other? Am J Hypertens 1988;1:335-347.

20 Pesce C, Menini S, Pricci F, Favre A, Leto G, DiMario U, Pugliese G: Glomerular cell replication and cell loss through apoptosis in experimental diabetes mellitus. Nephron 2002;90:484-488.

21 Marshall SM: The podocyte: A major player in the development of diabetic nephropathy? Horm Metab Res 2005;37:S9-16.

22 Welham SJ, Wade A, Woolf AS: Protein restriction in pregnancy is associated with increased apoptosis of mesenchymal cells at the start of rat metanephrogenesis. Kidney Int 2002;61:1231-1242.

23 Godley LA, Kopp JB, Eckhaus M, Paglino JJ, Owens J, Varmus HE: Wild-type p53 transgenic mice exhibit altered differentiation of the ureteric bud and possess small kidneys. Genes Dev 1996;10:836-850. 